\title{
Inhibition of 3-Phosphoglycerate Dehydrogenase by L-Serine
}

\author{
BY J. C. SLAUGHTER* AND D. D. DAVIES \\ School of Biological Sciences, University of East Anglia, Norwich NOR $24 B$
}

(Received 24 April 1968)

\begin{abstract}
1. L-Serine was shown to be a highly specific inhibitor of 3-phosphoglycerate dehydrogenase. 2. 3-Phosphoglycerate dehydrogenase is cold-labile with respect to its catalytic activity and to sensitivity to serine. 3. L-Serine protects the catalytic site as well as the inhibitor site. 4. Glycerol protects the catalytic site as well as the inhibitor site. 5. Serine acts as a 'classical' non-competitive inhibitor of fresh preparations of 3-phosphoglycerate dehydrogenase. 6. 'Aged' preparations when assayed at $\mathrm{pH} 6.5$ show sigmoid inhibition curves at saturating substrate concentrations. 7. A generalized model is advanced to account for the variation of the catalytic activity and the inhibitory effect of L-serine with time and conditions. 8. The possibility that the sigmoid kinetics of inhibition observed are an artifact of isolation is discussed.
\end{abstract}

The control of metabolic pathways through the mechanism of feedback inhibition is now well established (Atkinson, 1966; Stadtman, 1966). The actual mechanism by which enzyme activity is altered is not known and a variety of hypotheses exist. Many of the enzymes investigated have shown non-Michaelis kinetics and this behaviour has assumed an important position in any discussion of 'control' enzymes.

Monod, Wyman \& Changeux (1965) presented a detailed model to account for both homotropic and heterotropic effects. Their system relied on a subunit structure for the enzyme and they postulated that the enzyme existed in at least two forms in equilibrium. Co-operativity arose through displacement of this equilibrium as a result of ligandbinding. Koshland, Nemethy \& Filmer (1966) analysed several model systems of interaction between sub-units in which conformation changes were induced by ligand-binding. They also considered the model of Monod et al. (1965) and emphasized that a unique mechanism cannot be established from kinetic studies alone.

All explanations of heterotropic effects have assumed the existence of a non-catalytic regulator site specific to the modifier. Much recent work has concentrated on the explanation of homotropic effects and various assumptions have been made. Both groups of authors mentioned in the above paragraph assumed only one substrate site/sub-unit (the catalytic site). Co-operativity arose through the sub-unit nature of the enzyme. Rabin (1967)

* Present address: Department of Brewing and Biochemistry, Heriot-Watt University, Edinburgh, 1. proposed a model based on substrate-induced conformational change (enzyme activation) where only the active site was necessary and there was no requirement for a sub-unit structure.

However, several authors have proposed mechanisms for specific enzymes that involve two substrate sites (Atkinson, Hathaway \& Smith, 1965; Sanwal, Stachow \& Cook, 1965; Nakagawa \& Hayaishi, 1967). One site is catalytic and the other has a regulatory function.

The formation of serine from 3-phosphoglycerate via phosphohydroxypyruvate and phosphoserine has been shown in animals and bacteria (Pizer, 1964, 1963). The work of Hanford \& Davies (1958) suggested that this could also be the case in plants and the enzymes of this pathway have now been identified in etiolated pea epicotyls (Slaughter, 1967).

L-Serine has been shown to inhibit 3-phosphoglycerate dehydrogenase from bacteria (Pizer, 1963), but not that from animals (Walsh \& Sallach, 1965; Bridgers, 1965). In the latter case, phosphoserine phosphatase has been shown to be inhibited by low concentrations of $\mathrm{L}$-serine (Borkenhagen \& Kennedy, 1959). Slaughter (1967) has shown that 3-phosphoglycerate dehydrogenase from etiolated pea epicotyls is very sensitive to inhibition by L-serine, whereas the phosphoserine phosphatase from the same source is not.

Although 3-phosphoglycerate dehydrogenase has been identified as an enzyme open to feedback inhibition, little has been reported about the details of inhibition. The present paper describes further investigation into the nature of the interactions 
between L-serine and 3-phosphoglycerate dehydrogenase from peas. A preliminary report of the work has appeared (Slaughter \& Davies, 1967).

\section{MATERIALS AND METHODS}

Amino acids were obtained from Sigma Chemical Co. (St Louis, Mo., U.S.A.). Other materials and methods are given in the preceding paper (Slaughter \& Davies, 1968).

\section{RESULTS}

Inhibition of 3-phosphoglycerate dehydrogenase. The inhibitory effect of L-serine on 3-phosphoglycerate dehydrogenase present in crude extracts of peas was noted in the preceding paper (Slaughter \& Davies, 1968). The specificity of this inhibition was examined by testing various compounds as inhibitors of a freshly prepared extract in potassium phosphate buffer, pH 6.5 (0.1 M), containing glycerol $(2.5 \mathrm{M})$. The rate in oxidation of NADH by phosphohydroxypyruvate was measured and compared with the rate in the presence of various compounds at a concentration of $1 \mathrm{mM}$. L-Serine gave approx. $85 \%$ inhibition, but the following compounds were without effect: D-serine, 3-phospho-L-serine, glycine, pyruvate, D-glycerate, DL-homoserine, L- $\alpha$ aminobutyric acid, L-alanine, L-cysteine, Lthreonine, L-valine, ethanolamine and hydroxypyruvate.

Inhibition of 3-phosphoglycerate dehydrogenase by $\mathrm{L}$-serine at $\mathrm{pH} 5 \cdot 5$. The $\mathrm{pH}$ optimum for the enzyme acting in the direction of NADH oxidation is pH 5.5. The kinetics of $\mathrm{L}$-serine inhibition were examined at this $\mathrm{pH}$ with a crude extract prepared in potassium phosphate buffer, $\mathrm{pH} 6.5(0.1 \mathrm{M})$, containing glycerol $(2.5 \mathrm{M})$. The extract was passed through a column of Sephadex G-25 to remove small molecules. The kinetics of inhibition shown in Fig. 1 are linear when reciprocals are plotted and indicate that $\mathrm{L}$-serine behaved as a 'classical' non-

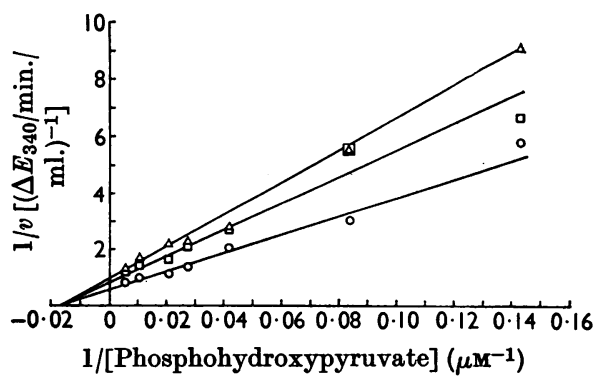

Fig. 1. Effect of L-serine on $V_{\max }$. and $K_{m}$ at pH5.5. A fresh crude extract was used after passage through Sephadex

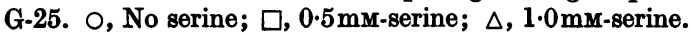

competitive inhibitor when the concentration of phosphohydroxypyruvate was varied.

Inhibition of 3-phosphoglycerate dehydrogenase by $\mathrm{L}$-serine at $\mathrm{pH} 6 \cdot 5$. When a freshly prepared extract was examined for its response to L-serine at $\mathrm{pH} \mathrm{6.5}$, the kinetics were those of 'classical' non-competitive

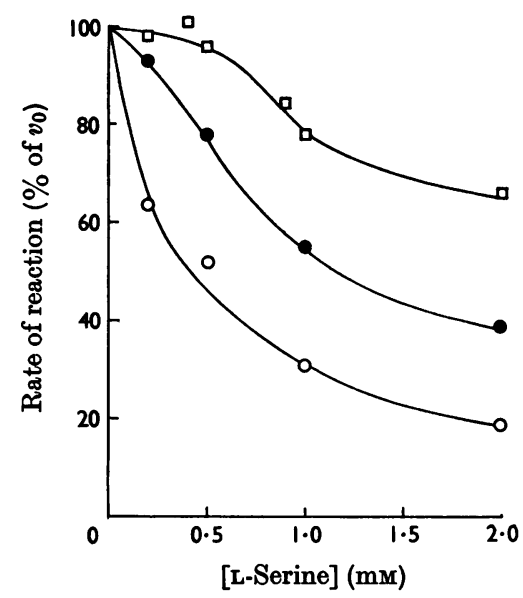

Fig. 2. Sigmoid inhibition curves obtained at pH6.5. A crude extract was prepared in potassium phosphate buffer, pH6.5 (0.10 M), containing glycerol $(2.5 \mathrm{M})$ and stored at $2^{\circ}$. The inhibitory effect of $\mathrm{L}$-serine was determined at intervals with a potassium phosphate assay buffer, pH6.5 (91 mM). $\bigcirc, \frac{1}{2} \mathrm{hr}$. from extraction; $\bullet, 1 \mathrm{hr}$. from extraction; $\square, 4 \mathrm{hr}$. from extraction.

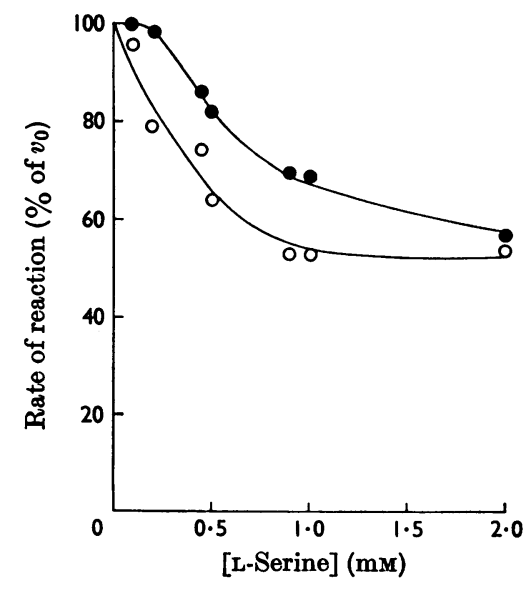

Fig. 3. Effect of pH on inhibition curves. A crude extract was prepared in potassium phosphate buffer, pH6.5 $(0 \cdot 10 \mathrm{M})$, containing glycerol $(2.5 \mathrm{M})$ and stored for $4 \mathrm{hr}$. at $2^{\circ}$. The inhibitory effect of L-serine was determined in tris-succinate assay buffer (91 mM) at two $\mathrm{pH}$ values. O, $\mathrm{pH} 5 \cdot 5 ; \bullet, \mathrm{pH} 6.5$. 
inhibition. However, when the extract was stored at $2^{\circ}$ for $4 \mathrm{hr}$. before examination of the kinetics of inhibition, a sigmoid response was observed (Fig. 2). Such kinetics conform to the allosteric V system of Monod et al. (1965). The sigmoid response to serine observed when aged extracts are assayed at pH 6.5

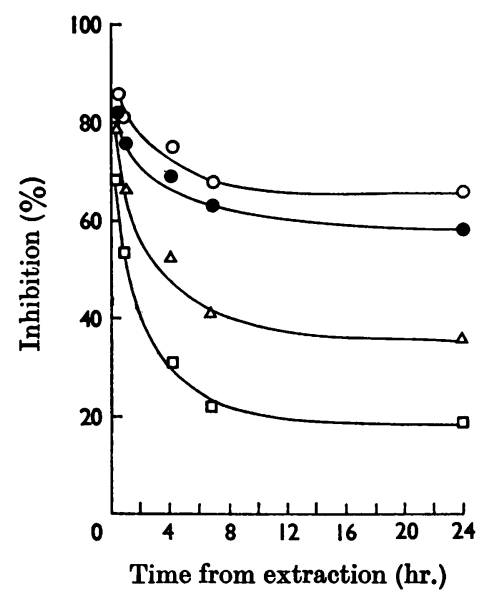

Fig. 4. Rate of loss of sensitivity to L-serine. The data from Fig. 12 are plotted to show the rate at which sensitivity to L-serine was lost at various assay concentrations of L-serine. $\square, 0.5 \mathrm{~mm}$-L-Serine; $\Delta, 1.0 \mathrm{mM}$-L-serine;, $2.0 \mathrm{mM}$ L-serine; O, 3.0mM-L-serine.

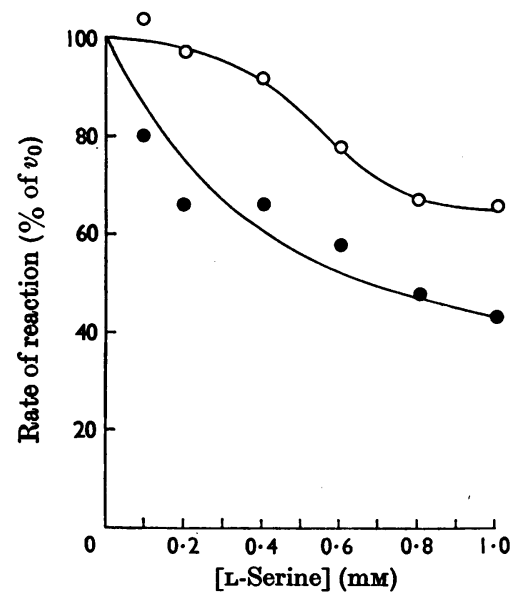

Fig. 5. Inhibition by L-serine and substrate concentration. $A$ crude extract prepared at $2^{\circ}$ in potassium phosphate buffer, pH6.5 (0.10M), containing glycerol $(2.5 \mathrm{M})$ was stored for $4 \mathrm{hr}$. at $2^{\circ}$. The extent of inhibition by L-serine was then determined at two substrate concentrations. The assay buffer was potassium phosphate, pH6.5 (91 mM). O, $190 \mu \mathrm{M}-P h o s p h o h y d r o x y p y r u v a t e ; 0,19 \mu \mathrm{M}$-phosphohydroxypyruvate. is not found when the same extracts are assayed at pH 5.5 (Fig. 3). A number of experiments performed at pH 5.5 have given slightly sigmoid curves, but in no case was the degree of sigmoidicity greater than the error involved in the assays. However, if the percentage inhibition produced by a given concentration of serine is plotted against age of extract, a series of curves is obtained whose initial slopes depend on the concentration of $L$-serine in the assay (Fig. 4). These results appear to show that the rate of loss of the inhibitory effect is greater when assay mixtures contain low concentrations of L-serine than when the $\mathbf{L}$-serine concentration is higher in the assay mixture. This is the result that would be expected if the inhibition curves at $\mathrm{pH} 5.5$ were tending to become more sigmoid with the age of the extract.

The sigmoid response to increasing concentrations of serine at pH6.5 depends on the substrate concentration (Fig. 5), and sigmoid kinetics are also observed when the velocity of the reaction is plotted against increasing substrate concentrations in the presence of a constant concentration of $\mathrm{L}$-serine (Fig. 6).

These results imply that at $\mathrm{pH} 6 \cdot 5$. L-serine can alter the $K_{m}$ for phosphohydroxypyruvate as well as lowering $V_{\max }$.

Effects of glycerol, serine and storage temperature on the catalytic activity of 3-phosphoglycerate dehydrogenase. The 3-phosphoglycerate dehydrogenase activity of an extract of etiolated pea epicotyls prepared in potassium phosphate buffer, pH 6.5 $(0.1 \mathrm{M})$, and stored at $2^{\circ}$ rose initially and then declined (Fig. 7). When $\mathrm{L}$-serine was added to

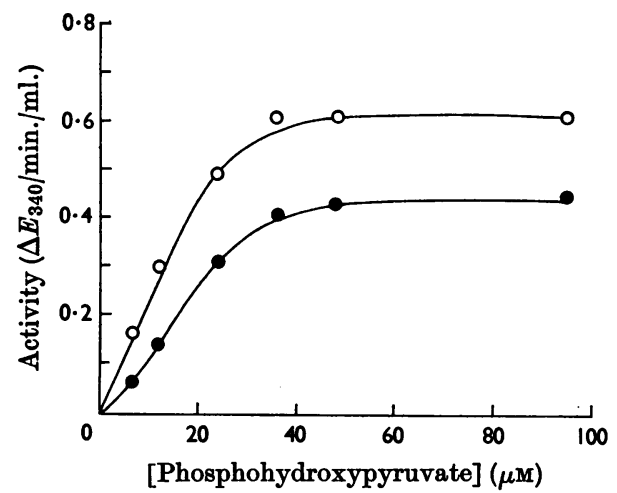

Fig. 6. Effect of L-serine on the Michaelis curve at $\mathrm{pH} 6 \cdot 5$. An extract was prepared in potassium phosphate buffer, pH6.5 (0.10 M), containing glycerol $(2.5 \mathrm{M})$ and stored for $4 \mathrm{hr}$. at $2^{\circ}$ before use. The NADH concentration was $0.20 \mathrm{M}$ and assays were carried out in potassium phosphate buffer, pH6.5 (91 mM). O, No serine added to assay mixture; , 1.0 mM-serine in assay mixture. 


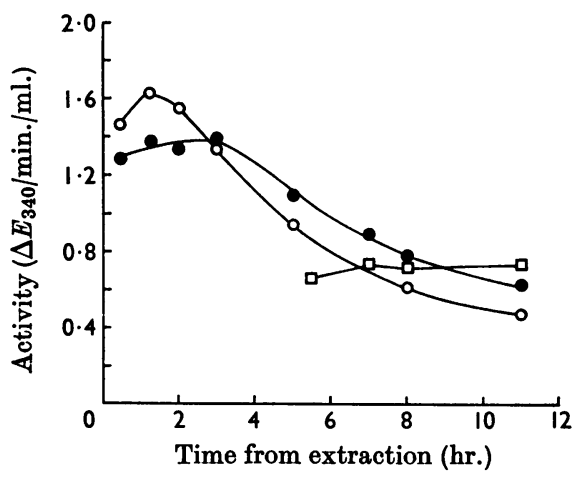

Fig. 7. Stability of catalytic activity at $2^{\circ}$. A crude extract was prepared at $2^{\circ}$ in potassium phosphate buffer, $\mathrm{pH} 6.5$ $(0.10 \mathrm{M})$, and stored at $2^{\circ}$. A portion was made $1.0 \mathrm{~mm}$ with respect to L-serine and also stored at $2^{\circ}$. After about $5 \mathrm{hr}$. a portion of the serine-free extract was made $2.5 \mathrm{M}$ with respect to glycerol and storage continued at $2^{\circ}$. Assays were carried out at pH 5.5. $O$, No added serine; $0,1.0 \mathrm{~mm}$ serine; $\square, 2.5$ M-glycerol.

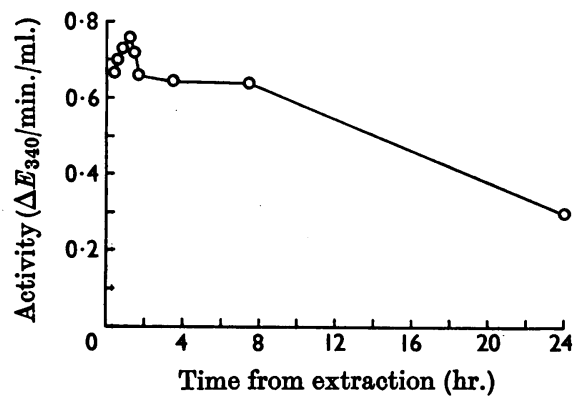

Fig. 8. Stability of catalytic activity at room temperature. A crude extract was prepared in potassium phosphate buffer, pH6.5 $(0.10 \mathrm{M})$, at room temperature and stored at this temperature. Assays were carried out at pH5.5.

the extract to give a final concentration of $1.0 \mathrm{mM}$ it decreased the rate at which the catalytic activity was lost. When a similar extract was stored at room temperature, a rapid rise and fall of activity was followed by a stable period and eventual loss of activity (Fig. 8). It thus appears that the catalytic activity is more stable at room temperature than at $2^{\circ}$, i.e. the enzyme is cold-labile.

When glycerol $(2.5 \mathrm{M})$ was included in the extracting medium, the enzyme activity varied with time as in the extract at room temperature, but over an extended time-scale (Fig. 9). It should be noted that the addition of glycerol to an extract prepared in potassium phosphate buffer and stored at $2^{\circ}$ until the catalytic maximum was passed did not produce a second maximum (Fig. 7).

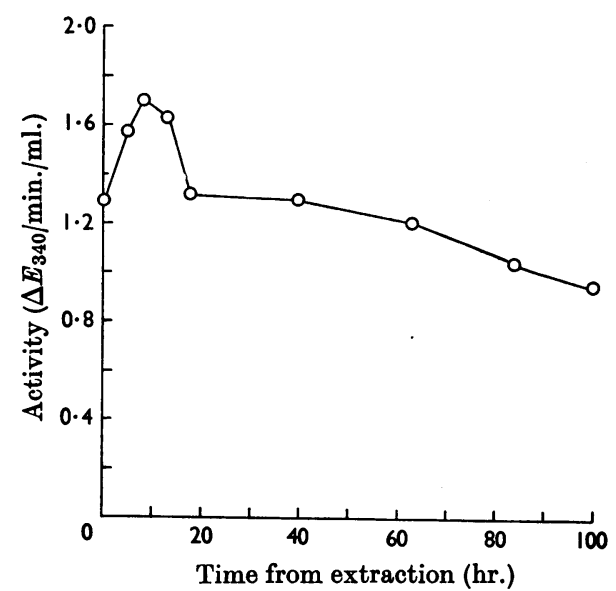

Fig. 9. Stability of the catalytic activity at $2^{\circ}$ in the presence of glycerol. A crude extract was prepared at $2^{\circ}$ in potassium phosphate buffer, $\mathrm{pH} 6.5(0 \cdot 10 \mathrm{M})$, containing glycerol $(2.5 \mathrm{M})$ and stored at $2^{\circ}$. Assays were carried out at pH5.5.

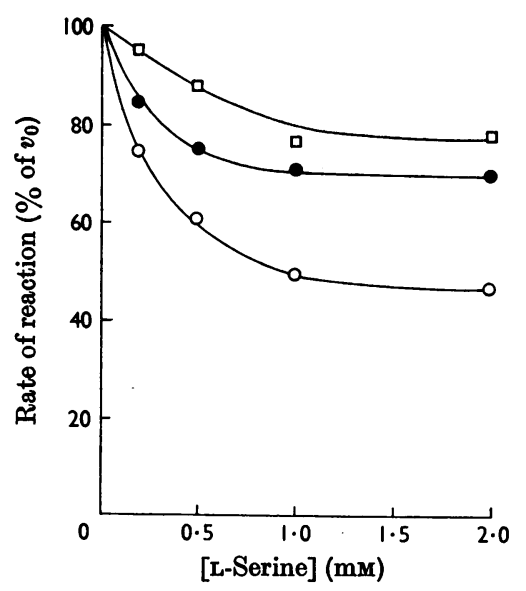

Fig. 10. Stability of the inhibitory property at $2^{\circ}$. The extract used was prepared at $2^{\circ}$ in potassium phosphate buffer, pH 6.5 (0.10 M), at $2^{\circ}$ and stored at this temperature. $v_{0}$ is the velocity in the absence of added serine. Assays were carried out at $\mathrm{pH} 5 \cdot 5.0, \frac{1}{2} \mathrm{hr}$. from extraction; $\bullet, 1 \mathrm{hr}$. from extraction; $\square, 2 \mathrm{hr}$. from extraction.

Effects of glycerol, L-serine and storage temperature on the inhibitory effect of L-serine. When an extract was prepared in phosphate buffer, $\mathrm{pH} 6.5(0.1 \mathrm{M})$, and stored at $2^{\circ}$, the effectiveness of serine as an inhibitor declined rapidly (Fig. 10).

When a similar extract was stored at room temperature, the inhibitory effect of L-serine declined rapidly at the outset and then passed 


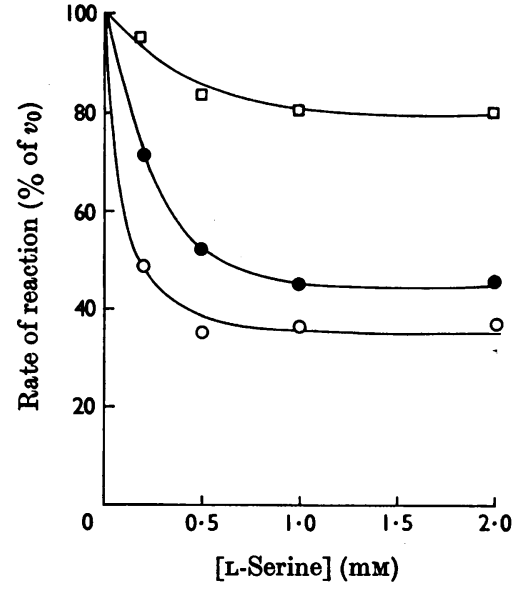

Fig. 11. Stability of the inhibitory property at room temperature. The extract used was prepared at room temperature in potassium phosphate buffer, pH 6.5 (0.10 M), and stored at the same temperature. Assays were carried out at pH5.5. $O, \frac{1}{2} \mathrm{hr}$. from extraction; $\bullet, 1 \frac{1}{2} \mathrm{hr}$. from extraction; $\square, 24 \mathrm{hr}$. from extraction. Curves obtained at $4 \frac{1}{2}$ and $7 \frac{1}{2} \mathrm{hr}$. from extraction were not sufficiently different from the $1 \frac{1}{2} \mathrm{hr}$. curve to be plotted separately.

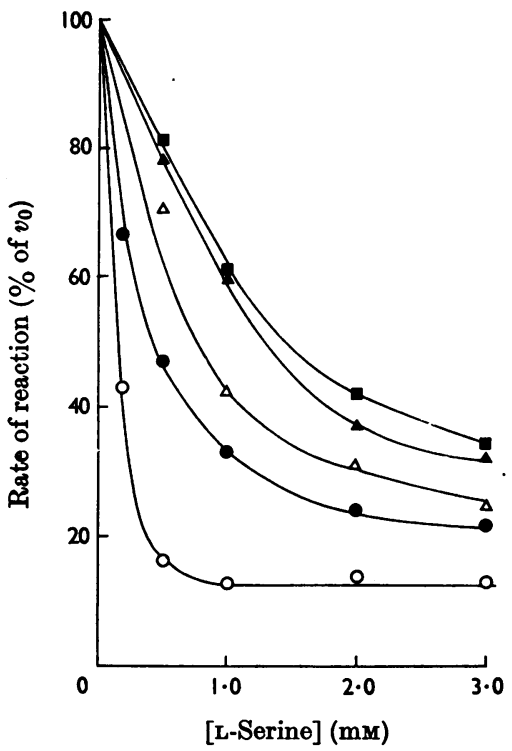

Fig. 12. Stability of the inhibitory property at $2^{\circ}$ in the presence of glycerol. A crude extract was prepared at $2^{\circ}$ in potassium phosphate buffer, $\mathrm{pH} 6.5(0 \cdot 10 \mathrm{M})$, containing glycerol $(2 \cdot 5 \mathrm{M})$ and stored at $2^{\circ}$. Assays were carried out at $\mathrm{pH5}$.5. $\mathrm{O}, 15 \mathrm{~min}$. from extraction; $\ominus, 1 \mathrm{hr}$. from extraction; $\Delta, 4 \mathrm{hr}$. from extraction; $\Delta, 7 \mathrm{hr}$. from extraction; $\square, 24 \mathrm{hr}$. from extraction.

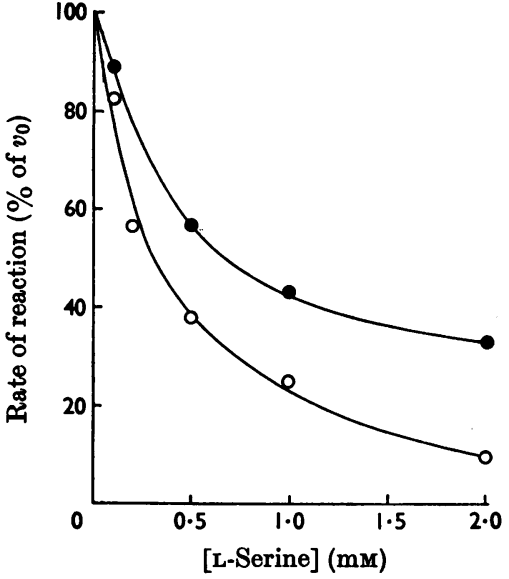

Fig. 13. L-Serine and the stability of the inhibitory property. A crude extract was prepared at $2^{\circ}$ in potassium phosphate buffer, pH6.5 (0.10M), containing glycerol $(2.5 \mathrm{M})$ and L-serine $(1.0 \mathrm{~mm})$. Storage was at $2^{\circ}$ and assays were carried out at pH5.5. O, $\frac{1}{2} \mathrm{hr}$. from extraction; $0,24 \mathrm{hr}$. from extraction.

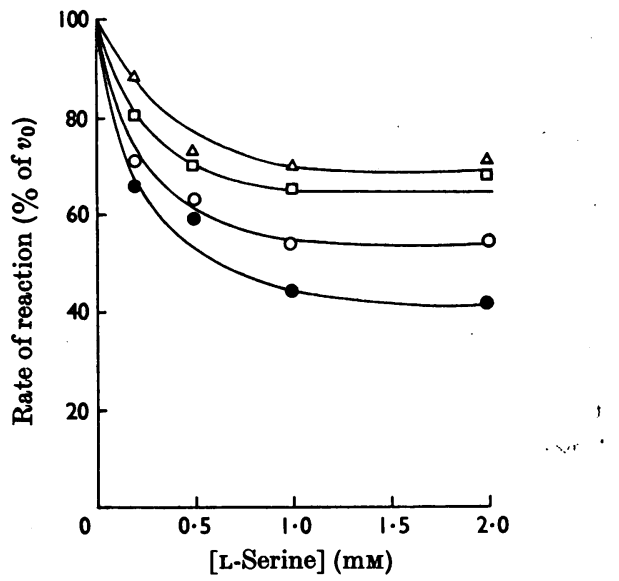

Fig. 14. Regeneration of the inhibitory property. A crude extract was prepared at $2^{\circ}$ in potassium phosphate buffer, pH 6.5 (0.10M). The extract was stored at $2^{\circ}$ for $75 \mathrm{~min}$., when a portion was transferred to a water bath at $25^{\circ}$. The effect of serine was determined at the following intervals: $\square, 75 \mathrm{~min}$. at $2^{\circ}$; $O, 75 \mathrm{~min}$. at $2^{\circ}, 30 \mathrm{~min}$. at $25^{\circ} ; \triangle, 120 \mathrm{~min}$. at $2^{\circ} ; 0,75 \mathrm{~min}$. at $2^{\circ}, 240 \mathrm{~min}$. at $25^{\circ} ; \Delta, 330 \mathrm{~min}$. at $2^{\circ}$.

through a stable period (Fig. 11). It thus appears that the inhibitory 'site' is also cold-labile.

When glycerol $(2.5 \mathrm{M})$ was included in the extracting medium and the extract stored at $2^{\circ}$, the sensitivity to serine was protected (Fig. 12).

When, in addition to glycerol, $\mathrm{L}$-serine was added 
to give a final concentration of $1.0 \mathrm{~mm}$, the sensitivity of 3-phosphoglycerate dehydrogenase to serine was further protected (Fig. 13).

The sensitivity to serine, which is rapidly lost at low temperature $\left(2^{\circ}\right)$, can be partially restored by incubating the extract at $25^{\circ}$ (Fig. 14).

\section{DISCUSSION}

Although direct combination of L-serine with a modifier site on 3-phosphoglycerate dehydrogenase has not been shown, the specificity of the inhibition, its non-competitive nature and the stabilizing effect of $L$-serine on catalytic activity imply that this is so. It would seem that the inhibition by L-serine is not an artifact, and it might have physiological significance as it could allow serine in the cell to control its own rate of synthesis.

Inhibition of 3-phosphoglycerate dehydrogenase by L-serine was shown to vary with age of extract and assay $\mathrm{pH}$. Depending on the conditions chosen the effect could be classified in a number of ways (nomenclature after Monod et al. 1965): (1) simple non-competitive (fresh extract at $\mathrm{pH} 5.5$ or $\mathrm{pH} \mathrm{6.5)}$; (2) heterotropic V system (aged extract at pH 5.5); (3) mixed heterotropic $V$ and $K$ system (aged extract at $\mathrm{pH} 6.5$; cf. Figs. 5 and 6 ).

This apparent variety of response can be accounted for on the assumption that stepwise degradation of the enzyme occurs on extraction. The simplest case where there is one intermediate between the fully active molecule and the inactive molecule is illustrated in Scheme 1.

Such a model provides an explanation of the way in which catalytic activity varies with time, as the occurrence of $\mathrm{B}$ must lead initially to a rise in activity with a subsequent fall as more of the enzyme passes over into the $\mathrm{X}$ form. The exact results obtained will depend on the rates and

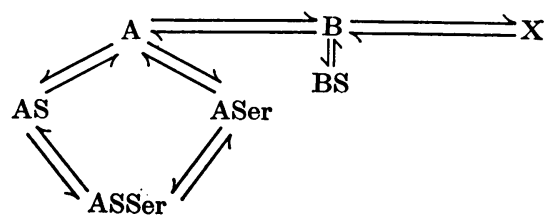

Scheme 1. Model for the behaviour of 3-phosphoglycerate dehydrogenase. A is the native form of the enzyme, which combines with substrate (S) and L-serine (Ser) so that serine acts as a non-competitive inhibitor. $B$ is the first degradation product. A loss of structure has occurred that renders L-serine ineffective as an inhibitor and results in a $V_{\max }$. higher than that for $\mathrm{A}$. $\mathrm{X}$ is the second degradation product; catalytic activity has been completely lost. All complexes between the various forms of enzyme and substrate or L-serine are formed rapidly. The overall equilibrium in the $A \rightleftharpoons X$ reaction lies greatly in favour of $X$. equilibrium positions of the two steps. Temperature and glycerol can be postulated to act at either of these two points. L-Serine in the incubation mixture will lead to formation of ASer and thereby decrease the rate of the $A \rightarrow B$ step by lowering the concentration of A.

The same model can also account for the various shapes of inhibition curve that have been obtained. On extraction, A will be the dominant form of the enzyme and simple inhibition curves will result. However, in a system where $B$ has increased to near its equilibrium concentration with $A$, addition of serine will not only cause formation of ASer but by thus lowering the concentration of $\mathbf{A}$ cause a reversion of some of the $B$ form to the $A$ form. As $A$ is postulated to be less catalytically active than $B$, this process will introduce sigmoidicity into the kinetics of serine inhibition.

Variation in the form of the inhibition curves with assay conditions can also be understood on this general model. The equilibrium positions and ratio of reaction will probably depend on assay conditions, as may the catalytic activity of the enzyme forms and the various $K_{m}$ values. On this type of scheme, whether or not an effect of serine is found on the apparent $K_{m}$ of the extract will depend on the $K_{m}$ values of the A and B forms. Regardless of such effects, serine must always depress $V_{\text {max., }}$ as this is the basic mechanism of its action on $A$.

Whatever interpretation is considered for the behaviour of 3-phosphoglycerate dehydrogenase the results in this paper indicate that all the co-operative effects develop on aging of the extract and do not occur with a freshly prepared extract. This implies that inhibition of 3-phosphoglycerate dehydrogenase by serine in vivo will follow a classical non-competitive mechanism rather than the more complex co-operative pattern.

It is of general interest that, if on extraction of an enzyme the native form came rapidly into equilibrium with a catalytically active degradation product and both forms satisfied the structural requirements described by Monod et al. (1965), then a system capable of showing both homotropic and heterotropic co-operative effects would have come about as an artifact of isolation.

We thank the Science Research Council for a grant to J.C.S.

\section{REFERENCES}

Atkinson, D. E. (1966). Annu. Rev. Biochem. 35, 85. Atkinson, D. E., Hathaway, J. A. \& Smith, E. C. (1965). J. biol. Chem. 240, 2682.

Borkenhagen, L. F. \& Kennedy, E. P. (1959). J. biol. Chem. 234, 849 . 
Bridgers, W. F. (1965). J. biol. Chem. 240, 4591.

Hanford, J. \& Davies, D. D. (1958). Nature, Lond., 182, 532.

Koshland, D. E., jun., Nemethy, G. \& Filmer, D. (1966). Biochemistry, 5, 365.

Monod, J., Wyman, J. \& Changeux, J. P. (1965). J. molec. Biol. 12, 88.

Nakagawa, A. \& Hayaishi, O. (1967). J. biol. Chem. 242, 1146.

Pizer, L. I. (1963). J. biol. Chem. 238, 3934.

Pizer, L. I. (1964). J. biol. Chem. 239, 4219.
Rabin, B. R. (1967). Biochem. J. 102, 22 c.

Sanwal, B. D., Stachow, C. S. \& Cook, R. A. (1965). Biochemistry, 4, 410.

Slaughter, J. C. (1967). Ph.D. Thesis: University of East Anglia.

Slaughter, J. C. \& Davies, D. D. (1967). Biochem. J. 104, 49 .

Slaughter, J. C. \& Davies, D. D. (1968). Biochem. J. 109, 743.

Stadtman, E. R. (1966). Advanc. Enzymol. 28, 41.

Walsh, D. A. \& Sallach, H. J. (1965). Biochemistry, 4, 1076. 